\title{
Fuzzy Estimation Analysis of Photovoltaic Model Parameters
}

\author{
Helal Al-Hamadi \\ Department of Information Science, College of Computing Sciences and Engineering, Kuwait University, Kuwait, \\ Kuwait \\ Email: helal3113@hotmail.com, helal.alhamadi@ku.edu.kw
}

Received 7 May 2015; accepted 10 July 2015; published 17 July 2015

\begin{abstract}
One of the challenges in accurately estimating Photovoltaic (PV) cell electric performance is the uncertainty of the model equivalent circuit parameters. The parameters considered in the study are the series resistance, shunt resistance, photo current, saturation current, and diode ideality factor. Parameter estimation for the PV cell equivalent circuit model is challenging due to the implicit transcendental relationship of the I-V characteristics of the cell. This paper presents a fuzzy logic based study for estimating the uncertainty of the cell parameters. The model parameters change with temperature and irradiance, are the source of uncertainties. Mathematical programming is used to estimate the fuzzy parameters. The approach is performed on practical data and the results of the analysis provide the estimation of the PV cell parameters. Results of this research yielding better estimated parameters compared with other methods using the Absolute Mean Error (AME).
\end{abstract}

\section{Keywords}

Photovoltaic Cell, Parameter Sensitivity, Fuzzy Logic, Diode Model, Modeling

\section{Introduction}

Renewable energy sources are gaining more interest in recent years and will be an increasingly important part of power generation in the coming years [1]. The photovoltaic (PV) system provides an alternative renewable energy resource due to its environment friendly natural source of energy. It generates electricity on-site in remote and isolated areas without transmission losses or greenhouse gas emissions. The electrical properties of the PV modules determine the cost and performance of PV plants. The use of accurate PV model parameters representing effective PV models is necessary for accurate performance evaluation and control. Due to degradation and ageing of the PV modules, the actual the actual values of module parameters dynamically differ from those provided by the manufacturer. Moreover, the PV cell is a semiconductor material which exhibits a non-linear transcendental characteristic together with the unpredictable of the operating conditions complicates the modeling process. An exact equivalent circuit and its associated mathematical model is essential for providing accurate I-V characteristics of the PV module. The estimation of the PV module parameters helps to design more efficient PV modules and predicting their performance and efficiency. Several models have been proposed 
to describe the solar cell characteristics [2]-[8]. A Double-diode solar cell model is considered in this project with the same identity factor. A lumped parameter equivalent circuit with to model the solar cell. The main parameters to simulate the I-V terminal characteristics of the solar cell are, photo current, saturation current, shunt resistance, series resistance, and diode identity factor. The electrical current produced by a solar cell depends on the intensity of the incident light and on its intrinsic properties. An accurate estimation of the cell parameters required for accurate performance evaluation [3].

Several methods are proposed in the literature to estimate model PV parameters. In [4] PV parameters estimation of the equivalent model current voltage characteristics using least squares fitting method is effectively applied with minimal errors. A Simulated annealing based approach is proposed in [5] for optimal estimation of solar cell model parameters. In [6], a numerical curve fitting procedures are used to estimate the cell model parameters: a non-linear two-point interval division was applied to extract local parameters from the current-voltage data at search measurement point. In [7] a methodology based on radial basis function neural networks to estimate the electrical characteristic curves of PV modules from the environmental operating conditions is presented. Particle swarm optimization (PSO) was effectively applied to extract the solar cell parameters in [9] [10]. A genetic algorithm utilizing isolated points obtained experimentally is used to determine the PV external current-voltage characteristic curve of a solar cell is presented in [11]. Using data commonly provided by panel manufacturers, measured environmental parameters, and semi-empirical equations, a theoretical approach is presented in [12] to evaluate the uncertainty of the PV cell model parameter. A new parameters extraction method based on the differential evolution technique is introduced [13]. The method fits the I-V curve better than genetic algorithm having a lower fitness value and faster execution time.

In [14], the adaptive neuro-fuzzy inference systems as an AI technique which combines the advantages of fuzzy logicand adaptive networks, is applied for PV parameters estimation. The adaptive neuro-fuzzy inference systems is also used in [15] for parameter estimation of one diode equivalent circuit model of PV modules.

The present paper introduces a fuzzy-based methodology for the parameters estimation of PV cell. Using the of the PV equivalent circuit, Figure 1, the PV cell five equivalent circuit parameters: series resistance, shunt resistance, diode photo current, diode reverse saturation current and diodeideality factor, are assumed to be a fuzzy parameters. Measurement I-V data of the PV cell are used to form a set of equations with fuzzy parameters. Least square methods are used to obtain the optimum parameters. The proposed technique could be applied to estimate the parameters of PV modules in order to account for ageing, performance degradation, and changes of operating conditions. The results obtained are compared with other techniques in the literature.

\section{PV Modeling}

Accurate estimation of the equivalent circuit parameters is important for control and performance evaluation of the PV cell. Manufacturer datasheet parameters are nominal values that are measured in factory under specific temperature, illumination, and weather conditions. The parameters values changes with time due to aging and the nonlinear transcendental nature of the PV cell. Therefore, for PC cells in different weather and degradation

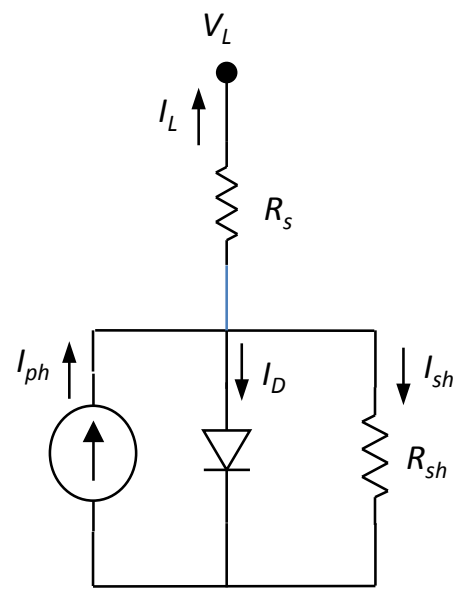

Figure 1. Equivalent circuit for a single diode lumped circuit. 
conditions the parameters must be estimated to obtain more accurate values than that given in the nominal manufacturing datasheet.

Solar photovoltaic power generation employs solar panels also called modules that composed of a number of solar cells containing semi-conductor photovoltaic diode(s) which converts solar radiation into electric current. Mathematically, the solar photovoltaic cell is modeled by current voltage relationship (I-V) which exhibits a non-linear relationship due to the semi-conductor behavior of the cell. This (I-V) characteristic of the solar cell can be presented by a single diode model [2], [3] and [5] shown in Figure 1, and mathematically presented by Equation (1) and Equation (2).

$$
\begin{gathered}
I_{L}=I_{p h}-I_{D}-I_{s h} \\
I_{L}=I_{p h}-I_{S D}\left[e^{\left(\frac{q\left(V_{L}+I_{L} R_{s}\right)}{n k T}\right)}-1\right]-\left[G_{s h}\left(V_{L}+I_{L} R_{s}\right)\right]
\end{gathered}
$$

where $I_{p h}, I_{S D}, n, R_{s}, G_{s h}=\left(1 / R_{s h}\right)$ being the photocurrent, the diode saturation current, the diode identity factor, the series resistance and the shunt conductance, respectively. IL and VL are the terminal Current and voltage respectively; $(\mathrm{q} / \mathrm{kT})$ is the inverse thermal voltage, where $\mathrm{k}$ is Boltzmann's constant $\left(1.3806503 \times 10^{-23} \mathrm{~J} / \mathrm{K}\right)$; q is the electronic charge $\left(1.602176565 \times 10^{-19} \mathrm{C}\right)$ and $\mathrm{T}$ is the cell absolute temperature in Kelvin.

\section{Fuzzy Logic Algorithm}

The research idea is based on the fact that system parameters could be deduced if their values are bounded by using a fuzzy logic algorithm. Using measured data together with fuzzy logic a set of equations are formed with fuzzy input fuzzy parameters. Then Least squares are used to obtain the optimal estimated parameters based on the formulation in [18] and [19]. In this algorithm, PV input current and voltage has been taken as input, and error between the estimated values of the input current and the calculated one has been calculated as output. The flow chart of Figure 2 represents the basic concept of the algorithm.

The equation of error and signal is given below as follows:

$$
\Delta I_{L}=\left|I_{L}-\hat{I}_{L}\right|
$$

where, $I_{L}$ is the measured PV terminal current, and $\hat{I}_{L}$ is the estimated current.

A triangular shaped membership function is used for the input parameters. The range of the signal has been selected appropriate to each variable. Figure 3 represents the graphical view of the membership function for $R_{s}$.

\section{Results}

Estimation of the five parameters of the PV module is illustrated in this section. Real photovoltaic solar module terminal data $\left(\mathrm{V}_{\mathrm{Li}}, \mathrm{I}_{\mathrm{Li}}\right)$ for $\mathrm{i}=1, \ldots, \mathrm{N}$ are considered in this testing [5]. The resulting parameters with comparison with previous work using other techniques are presented in Table 1. The comparison is based on the Absolute Mean Error (AME). For each method the estimated resulting parameters along with current the measured terminal are used to calculate the terminal voltage. The AME of the calculated and measured voltages are computed and presented in Table 1.

\section{Conclusion}

The paper presents a fuzzy-logic based technique to estimate the equivalent circuit parameters of PV cell. The PV cell five equivalent circuit parameters are modeled to be fuzzy parameters. Measurement I-V data of the PV

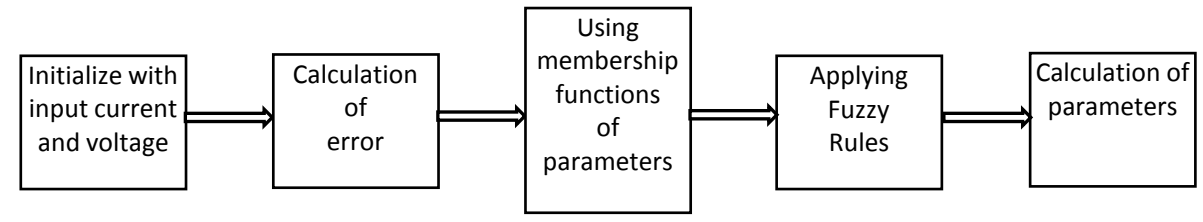

Figure 2. Fuzzy logic algorithm. 


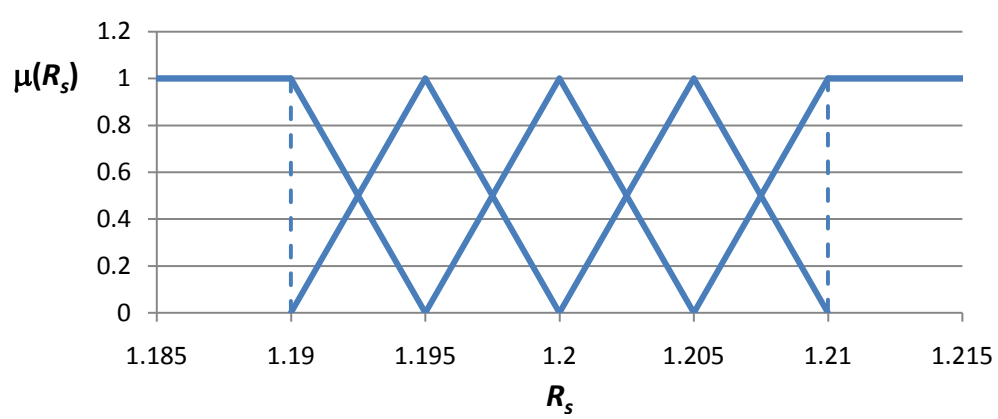

Figure 3. Graphical views of the membership function for $R_{s}$.

Table 1. Comparisons of estimated parameters by this technique and previous work.

\begin{tabular}{ccccc}
\hline & Ref. [16] & Ref. [17] & Ref. [5] & This work \\
\hline $\mathrm{I}_{\mathrm{ph}}(\mathrm{A})$ & 1.0313 & 1.0339 & 1.0331 & 1.0341 \\
$\mathrm{I}_{\mathrm{sd}}(\mu \mathrm{A})$ & 3.1756 & 3.076 & 3.6642 & 3.6391 \\
$\mathrm{R}_{\mathrm{s}}(\Omega)$ & 1.2053 & 1.203 & 1.1989 & 1.2019 \\
$\mathrm{G}_{\mathrm{sh}}\left(\Omega^{-1}\right)$ & 0.0014 & 0.0018 & 0.0012 & 0.0015 \\
$\mathrm{n}$ & 48.2889 & 48.1862 & 48.8211 & 48.1849 \\
Error(MAE) & 0.175367 & 0.183851 & 0.026887 & 0.016638 \\
\hline
\end{tabular}

cell are used to form a set of equations with fuzzy parameters. Least square methods are used to obtain the optimum parameters. The proposed technique could be applied to estimate the parameters of PV modules in order to account for ageing, performance degradation, and changes of operating conditions. The results obtained are compared with other techniques in the literature yielding better estimated parameters compared with other methods using the Absolute Mean Error (AME).

\section{Acknowledgements}

The research is commissioned and financially supported by Kuwait University Research Sector under grant WI01/13.

\section{References}

[1] Renewables 2010 Global Status Report. 2010. http://www.rona.unep.org/documents/news/Renewables-GlobalStatusReport2010_pre-release_en_full.pdf

[2] Adamo, F., Attivissimo, F., Di Nisio, A. and Spadavecchia, M. (2011) Characterization and Testing of a Tool for Photovoltaic Panel Modeling. IEEE Transactions on Instrumentation and Measurement, 60, 1613-1622. http://dx.doi.org/10.1109/TIM.2011.2105051

[3] Villalva, M.G., Gazoli, J.R. and Filho, E.R. (2009) Comprehensive Approach to Modeling and Simulation of Photovoltaic Arrays. IEEE Transactions on Power Electronics, 24, 1198-1208. http://dx.doi.org/10.1109/TPEL.2009.2013862

[4] Ikegami, T., Maezono, T., Nakanishi, F., Yamagata, Y. And Ebihara, K. (2001) Estimation of Equivalent Circuit Parameters of PV Module and Its Application to Optimal Operation of PV System. Solar Energy Materials and Solar Cells, 67, 389-395. http://dx.doi.org/10.1016/S0927-0248(00)00307-X

[5] El-Naggar, K.M., Al Rashidi, M.R., Al Hajri, M.F. and Al-Othman, A.K. (2012) Simulated Annealing Algorithm for Photovoltaic Parameters Identification. Solar Energy Journal, 86, 266-274.

[6] Munji, M.K., Okullo, W., Van Dyk, E.E. and Vorster, F.J. (2010) Local Device Parameter Extraction of a Concentrator Photovoltaic Cell under Solar Spot Illumination. Solar Energy Materials and Solar Cells Journal, 94, 2129-2136. http://dx.doi.org/10.1016/j.solmat.2010.06.041

[7] Bonanno, F., Capizzi, G., Graditi, G., Napoli, C. and Tina, G.M. (2012) A Radial Basis Function Neural Network 
Based Approach for the Electrical Characteristics Estimation of Aphotovoltaic Module. Applied Energy, 97, 956-961. http://dx.doi.org/10.1016/j.apenergy.2011.12.085

[8] Xiao, W., Lind, M.G.J., Dunford, W.G. and Capel, A. (2006) Real-Time Identification of Optimal Operating Points in Photovoltaic Power Systems. IEEE Transactions on Industrial Electronics, 53, 1017-1026. http://dx.doi.org/10.1109/TIE.2006.878355

[9] Ye, M., Wang, X. and Xu, Y. (2009) Parameter Extraction of Solar Cells Using Particle Swarm Optimization. Journal of Applied Physics, 105, 094502-094508. http://dx.doi.org/10.1063/1.3122082

[10] Qin, H.S. and Kimball, J.W. (2011) Parameter Determination of Photovoltaic Cells from Field Testing Data Using Particle Swarm Optimization. IEEE Power and Energy Conference at Illinois (PECI), 1-4.

[11] Petcuţ, F.M. and Dragomir, T.L. (2010) Solar Cell Parameter Identification Using Genetic Lgorithms. Journal of Control Engineering and Applied Informatics, 12, 30-37.

[12] Attivissimo, F., Di Nisio, A., Savino, M. and Sapada Vecchia, M. (2012) Uncertainty Analysis in Photovoltaic Cell Parameter Estimation. IEEE Transactions on Instrumentation and Measurement, 61, 1334-1342.

[13] Ishaque, K., Salam, Z., Taheri, H. and Shamsudin, A. (2011) Parameter Extraction of Photovoltaic Cell Using Differential Evolution Method. IEEE Applied Power Electronics Colloquium (IAPEC), 10-15.

[14] Kalika, S., Rajaji, L. and Gupta, S. (2012) Intelligent Technique Based Modeling for PVPS. International Journal of Engineering and Innovative Technology (IJEIT), 2, 211-215.

[15] Kulaksız, A.A. (2011) ANFIS-Based Parameter Estimation of One Diode Equivalent Circuit Model of PV Modules. Proc. IEEE International Symposium on Computational Intelligence and Informatics (CINTI), 415-420.

[16] Easwarakhanthan, T., Bottin, J., Bouhouch, I. and Boutrit, C. (1986) Nonlinear Minimization Algorithm for Determining the Solar Cell Parameters with Microcomputers. International Journal of Solar Energy, 4, 1-12. http://dx.doi.org/10.1080/01425918608909835

[17] Bouzidi, K., Chegaar, M. and Nehaoua, N. (2007) New Methods to Extract the Parameters of Solar Cells from Their Illuminated I-V Curve. 4th International Conference on Computer Integrated Manufacturing Setif, Algeria.

[18] Sherali, H.D. and Alameddine, A. (1992) A New Reformulation-Linearization Technique for Bilinear Programming Problems. Journal of Global Optimization, 2, 379-410. http://dx.doi.org/10.1007/BF00122429

[19] Sherali, H.D. (2001) On Mixed-Integer Zero-One Representations for Separable Lower-Semicontinuous PiecewiseLinear Function. Operation Research Journal, 28, 155-160. http://dx.doi.org/10.1016/s0167-6377(01)00063-3 